\title{
Objective measures of non-adherence in cardiometabolic diseases: a review focused on urine biochemical screening
}

This article was published in the following Dove Medical Press journal: Patient Preference and Adherence

\author{
Dan Lane ${ }^{1,2}$ \\ Prashanth Patel ${ }^{2,3}$ \\ Kamlesh Khuntil \\ Pankaj Gupta ${ }^{2,3}$ \\ 'Leicester Diabetes Centre, University \\ of Leicester, Leicester General \\ Hospital, Leicester, UK; ${ }^{2}$ Department \\ of Chemical Pathology and Metabolic \\ Diseases, Leicester Royal Infirmary, \\ Leicester, UK; ${ }^{3}$ Department of \\ Cardiovascular Sciences, University of \\ Leicester, Leicester, UK
}

\begin{abstract}
Cardiometabolic diseases are among the most prevalent and harmful conditions worldwide. They are complex, comorbid conditions that require polypharmacy - a known contributor to non-adherence in cardiovascular disease (CVD) and diabetes mellitus (DM). Suboptimal adherence is associated with poor disease control, which increases the risk of hospitalizations, mortality, and preventable financial implications. However, until recently, the lack of a gold standard for non-adherence testing in cardiometabolic diseases has been the major barrier for understanding true prevalence and mortality consequences. Recent European guidelines have endorsed biochemical testing as the preferred measure for non-adherence in CVD, with urinary screening methods being the most clinically widespread. The diagnostic and therapeutic benefits incurred to health service resources by use of biochemical non-adherence testing are vast, as hospitalizations and associated economic burdens are reduced, and tailored therapies are increased. However, biochemical testing can only signify a snap shot of adherence behavior, and true adherence may be skewed by pharmacokinetic factors. This review summarizes current literature regarding the prevalence, impact, and reasons of non-adherence in cardiometabolic disease. The benefits of current adherence diagnostic tools have been appraised, where urine in biochemical testing has been focused upon and evaluated against other matrices. Keywords: adherence, biochemical test, cardiovascular disease, diabetes mellitus, LC-MS/MS
\end{abstract}

\section{Introduction}

Cardiometabolic diseases encompass metabolically linked conditions such as cardiovascular disease (CVD) and diabetes mellitus (DM). The epidemiology of these diseases is multifactorial and is influenced by environmental socioeconomics, lifestyle, and genetic factors. ${ }^{1}$ Polypharmacy is commonplace in people with cardiometabolic diseases as medications are largely diverse to tailor specific groups, ${ }^{2}$ and among other reasons (Figure 1), it is a key contributor to non-adherence.

Adherence to a treatment regime has been defined by a WHO report as the extent to which a patient's history of therapeutic medication-taking coincides with the prescribed treatment regimen, and the failure to do so is termed as non-adherence. ${ }^{3}$ Strong emphasis was made in the WHO report to differentiate adherence from compliance and concordance, as they imply that patients are not active in their own care.

Non-adherence in cardiometabolic disease is commonplace, despite the wide availability of treatment, and is also a key factor in poor clinical outcomes such as hospitalization and mortality., ${ }^{4,5}$ A UK-based study found non-adherence to be a main contributor in the annual cost of post-discharge medication harm (£396 million) as $90 \%$ of these costs were the result of hospital readmissions. ${ }^{6}$ Improving antidiabetic
Correspondence: Dan Lane Department of Chemical Pathology and Metabolic Diseases, Leicester Royal Infirmary, Level 4, Sandringham Building, LEI 5WW, UK

Tel +4401162587589

Email dan.lane@uhl-tr.nhs.uk
Patient Preference and Adherence 2019:13 537-547

537 


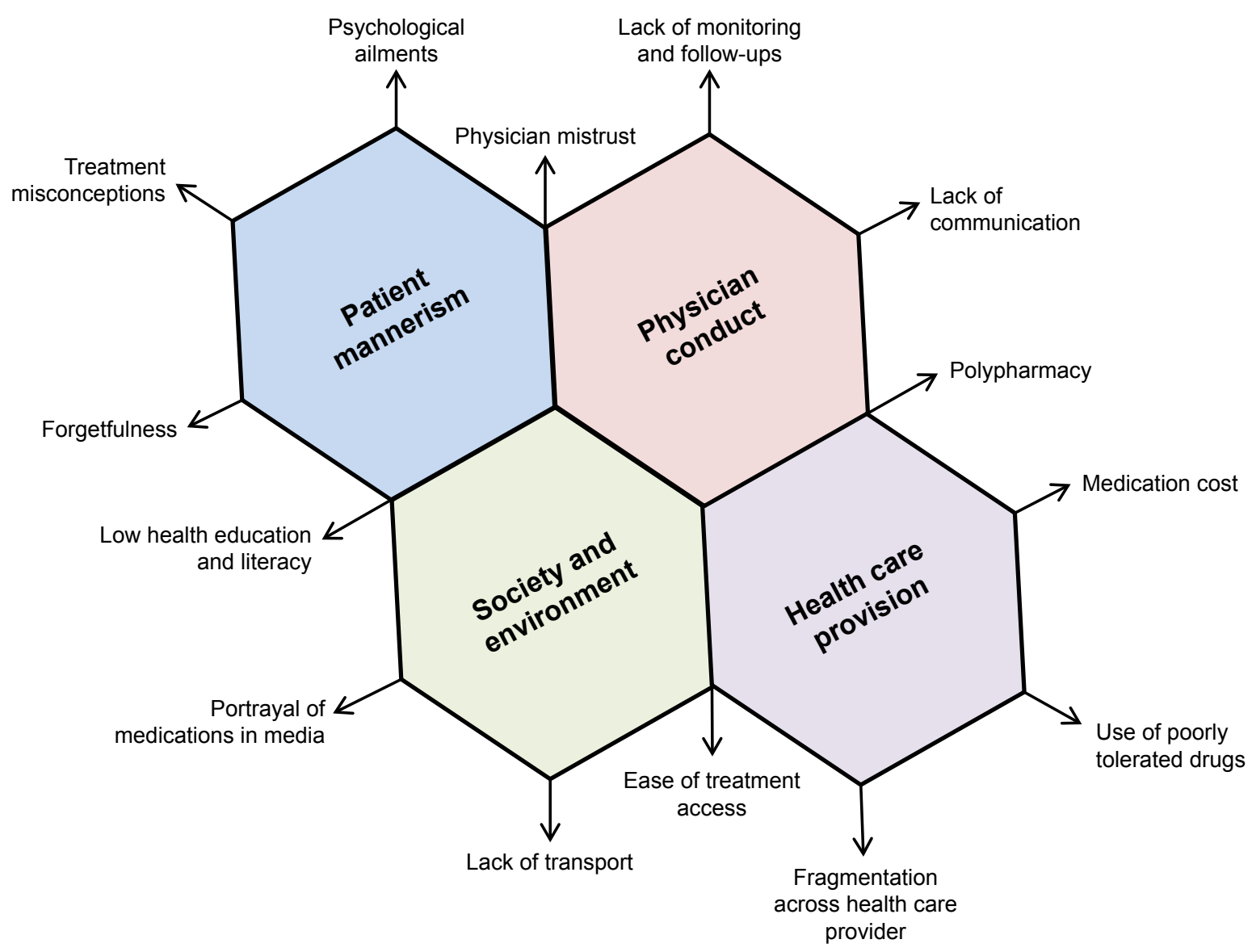

Figure I Barriers to overcome for tackling non-adherence. Notes: The four classes that contribute to non-adherence. ${ }^{17}$

medication non-adherence alone in USA is estimated to save between $\$ 0.661$ and $\$ 1.160$ billion annually. ${ }^{7}$ Haynes et al ${ }^{8}$ suggested that increasing the efficacy of adherence interventions could have a far larger effect on population health than any enhancement of specific treatments. It is therefore imperative to address non-adherence.

Studies have demonstrated the benefits of tailored interventions for non-adherence. The key obstacle for overcoming non-adherence is the current lack of suitable and accurate diagnostic tools. ${ }^{9}$ Current subjective methods for assessing adherence have negative bias and often overreport the number of ingested medications. ${ }^{10}$ Biochemical testing for non-adherence is a promising objective methodology that can decipher whether a patient has ingested the prescribed medication. Its use has been exemplified in urine for clinical diagnosis of resistant hypertension, ${ }^{11}$ however, these methods are traditionally expensive, lengthy, and largely unavailable.

The primary aim of performing this review was to explore the benefits of current adherence diagnostic tools, with a focus on urinary biochemical testing. This review has also sought to condense current literature regarding the prevalence, impact, and reasoning of non-adherence in CVD and DM.

\section{Non-adherence in CVDs and DM}

Mortality rates in CVDs increased by $14.5 \%$ between 2006 and 2016 and are the current leading cause of death worldwide. ${ }^{12}$ The WHO considers CVD, along with DM, as high priority non-communicable diseases. Approximately 422 million adults were afflicted with DM in 2014, with the global diagnosed population almost doubling since 1980 (4.7\%-8.5\% in 2014) ${ }^{13}$ and recent projections estimate that 693 million adults will have DM by $2045 .{ }^{14}$ In 2012, DM was the 8th leading cause of mortality with 1.5 million people dying from disease complications including kidney failure, stroke, and heart attack. ${ }^{15}$ Persons with DM have a 1.7-fold higher risk of CVD-attributed death. ${ }^{16}$

Evidently, CVD and DM are highly prevalent and have high associated morbidity, and so achieving good adherence in the population is essential. 


\section{Causes of non-adherence}

Forgetfulness, lack of physician communication, drug intolerance, and polypharmacy are all known contributors to non-adherence (Figure 1). ${ }^{17} \mathrm{~A}$ holistic approach is needed to overcome barriers for good adherence, yet, it has been estimated that in $40 \%$ of the consultations, physicians and health care professionals do not address adherence. ${ }^{10}$ Physicians often lack time to assess non-adherence, but the lack of an available, effective measure has also been a hurdle.

The misconceptions that patients have toward their treatments are suggested to be a key factor for non-adherence. Most of the cardiometabolic diseases are asymptomatic, and so treatment education has an important role to play for downplaying perceived wellness. Poor health education can lead to negative patient beliefs too. A cohort of Swedish stroke patients found that those with positive beliefs about their medicines were less likely to be non-adherent. ${ }^{18}$ Furthermore, an ischemic heart disease study found that patients with high beliefs in the harmful treatment repercussions revealed the predictors of non-adherence. ${ }^{19}$

Medication class can also affect non-adherence rates. Statins, an extensively prescribed group of drugs that reduce lipid synthesis by 3-hydroxy-3-methylglutaryl-CoA (HMG$\mathrm{CoA}$ ) reductase inhibition, have been shown to have higher non-adherence rates compared to other medications (Figure 2). In one study, non-adherence was $21 \%$ for statins versus $8 \%$ for glucose-lowering drugs. ${ }^{20}$ The degree to which a patient experiences side effects may explain these differences. Researchers found that $62 \%$ of people stop taking statins following side effects; ${ }^{21}$ however, patients could learn that many symptoms (eg, statin-associated muscle symptoms) are completely reversible through dose reduction and cessation.

Proprotein convertase subtilisin/kexin type 9 inhibitors (PCSK9i) are a new class of protein-based drugs that reduce low-density lipoprotein cholesterol. ${ }^{22}$ One study comparing non-adherence of PCSK9i and statins found adherence rates to be $79.4 \%$ and $30.9 \%$, respectively. ${ }^{23}$ Similarly, a study investigating drug safety and adherence found that $87 \%$ of the patients $(\mathrm{N}=27 / 31)$ indicated good adherence for PCSK9i using a self-report questionnaire form. ${ }^{24}$ However, the power of both studies was low due to the small population sizes investigated. These adherences may be better in PCKS9i as they cause less myalgia side effects, and they are only injected once every 2 weeks rather than daily.

\section{Polypharmacy and non-adherence}

An important cause of non-adherence is polypharmacy, which is the result of multimorbidity and therapy resistance. Multimorbidity is defined as the presence of 2 or more chronic medical diseases, like those in cardiometabolic disease. ${ }^{25} \mathrm{~A}$ recent comprehensive UK-based study of 403,985 patients found multimorbidity in $27.2 \%$ of the population, and those patients accounted for $78.4 \%$ of total prescriptions. ${ }^{26}$ The coexistence of these diseases typically complicates management, and the resultant polypharmacy can burden patients with an elevated risk of non-adherence, mental health difficulties, and adverse drug events. ${ }^{27}$

One systematic review found that $80 \%$ of the studies $(\mathrm{N}=4 / 5)$ had negative associations between polypharmacy and adherence. ${ }^{28}$ Another study found that non-adherence

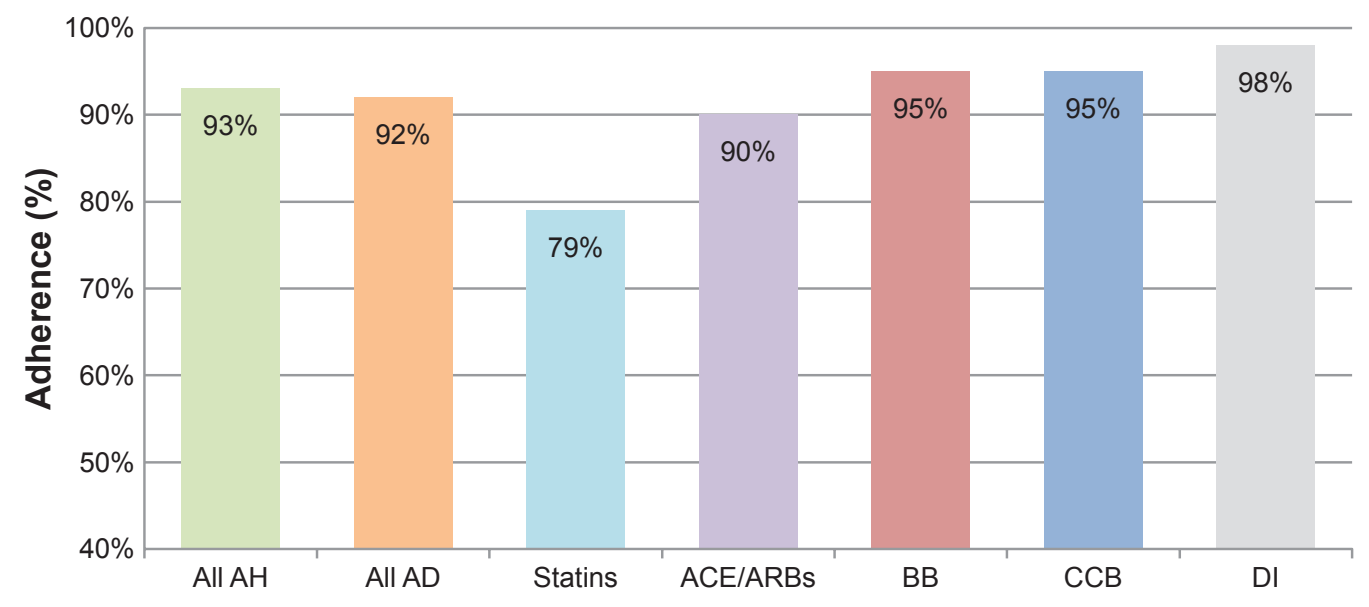

Figure 2 Adherence rates of different drug classes of cardiovascular disease and type 2 diabetes mellitus.

Notes: Adherence rates determined through biochemical testing in 256 patients. Minimally adapted from Atheroscler Suppl, Gupta P, Mohamed AA, Patel P, et al, 34 , High rates of non-adherence to antidiabetic, antihypertensive and lipid lowering treatment in patients with type 2 diabetes revealed liquid chromatography-tandem mass spectrometry (lc-ms/ms) urine analysis, e2, Copyright 2018, ${ }^{20}$ with permission from Elsevier.

Abbreviations: $A C E / A R B s$, angiotensin-converting enzyme inhibitors/angiotensin II receptor antagonists; $A D$, antidiabetics; $A H$, antihypertensives; $B B$, beta blockers; $\mathrm{CCB}$, calcium channel blockers; DI, diuretics. 
rates in hypertension patients increased 2-fold with each incremental pill addition, with the researchers also identifying age and gender as factors for non-adherence. ${ }^{29}$ This polypharmacy can be tackled with the implementation of combination pills (or polypills).

The European Society of Cardiology (ESC) and European Society of Hypertension (ESH) 2018 guidelines recommend the favoring of polypills when prescribing as they reduce polypharmacy and increase adherence. ${ }^{2}$ However, these medications tend to be expensive. For example, the expired patents for simvastatin and ezetimibe have resulted in the generic drugs costing $£ 0.55$ and $£ 2.94$, respectively, per month per patent. ${ }^{30,31}$ In comparison, Vytorin (combination of simvastatin and ezetimibe) retails at the cost of $£ 33.42$ per month per patient as a patented formulation. ${ }^{32}$

\section{Non-adherence prevalence}

A meta-analysis exploring CVD and antidiabetic medications found relatively high good adherence for the latter drug class at 69\% (95\% CI: 59-78), with good adherence being defined as $\geq 80 \%$ of the pharmacy refill rates in all medications. ${ }^{33} \mathrm{CVD}$ medications mostly had lower adherence rates, with statins and antihypertensives (AHs) at 54\% and 58\%, respectively. However, rates were calculated after incorporating only 2 studies for antidiabetic non-adherence versus 12 studies for the other CVD drugs due to the lack of available literature.

Research broadly agrees that non-adherence is common in people with DM; however, studies presenting non-adherence prevalence generally have inconsistent findings (38\%-93\% poor adherence). ${ }^{34}$ This inconsistency is also found when considering medication persistence (adherence over time), with a systematic review presenting rates between 41 and $81 \%$ over six studies. ${ }^{35}$ These variations can be mostly attributed to fluctuating definitions and methods used to diagnose adherence. Cohort size is another contributor here, as demonstrated in Figure 2 whereby DM medications have relatively high adherence compared to other studies. Regardless, there are still a significant proportion of people not taking their medications in DM.

\section{Non-adherence outcomes}

A retrospective study of 2,463 patients with type 2 DM (T2DM) found that the non-adherent patients (35\%) were 2.6-fold more likely to be hospitalized. ${ }^{36}$ Other studies have demonstrated these hospitalization rates, ranging from 1.3-fold to 2.5-fold in poorly adherent T2DM pateints. ${ }^{37,38}$ Mortality consequences in T2DM from non-adherence have been investigated by Currie et al who found an HR of 1.58
(95\% CI: 1.17-2.14) for patients who had poor adherence. ${ }^{39}$ Another study reflected these findings and showed that poorly adherent T2DM patients were $45 \%$ more to reach all-cause mortality versus adherent patients. ${ }^{40}$ Despite these data, a recent meta-analysis concluded that there were limited trials that have adequately investigated outcomes related to poor adherence in T2DM. ${ }^{5}$

In contrast, non-adherence-related mortality and morbidity risks in CVDs are better researched than in DM. Nonadherence rates as high as $58 \%$ have been reported from a recent meta-analysis of 376,162 patients. ${ }^{41}$ In their review of large primary trials, Kolandaivelu et al studied the repercussions of not following treatment sufficiently in CVD and found an increased likelihood of adverse consequences. ${ }^{42}$ They concluded that CVD non-adherence is currently at a pandemic level and is a leading risk factor for poor outcomes. The same study found that even after hospital admission for myocardial infarction, only $66 \%$ of the patients were adherent. This finding is not novel as other groups have found similar medication discontinuation after CVD events (11.5\% non-adherence after 1-year). ${ }^{43}$

Figure 3 demonstrates the mortality risk of non-adherence in people on AHs. These data were compiled from a large cohort $(\mathrm{N}=34,716)$ of a randomized selection of the Korean population over 8 years. ${ }^{44}$ For each CVD event, worsening adherence increased the HR and mortality risk. The study concluded that all-cause mortality and CVD were inversely related to superior $\mathrm{AH}$ adherence.

\section{Diagnostic tools for non-adherence}

The accuracy, robustness, and sensitivity of various diagnostic approaches used to assess non-adherence are discussed in this section. Subjective methods are based on a health care provider or patient evaluations and hence are generally simplistic, inexpensive, and quick. They are proxy measures that are inherently subjective as the evaluation depends on the reporter's mannerisms and self-belief. These methods have traditionally been the most widespread and implemented adherence assessments. ${ }^{45}$

Objective methodologies are based less on perception and can indirectly or directly assess adherence. Pill counting and reviewing pharmacy records are indirect objective tools that are used to infer patients' adherence. Digital pills and biochemical testing are direct assessments that provide robust data as to whether a medication has been ingested. The two approaches for adherence testing are used dependent on circumstance and both come with benefits and drawbacks (Table 1). 


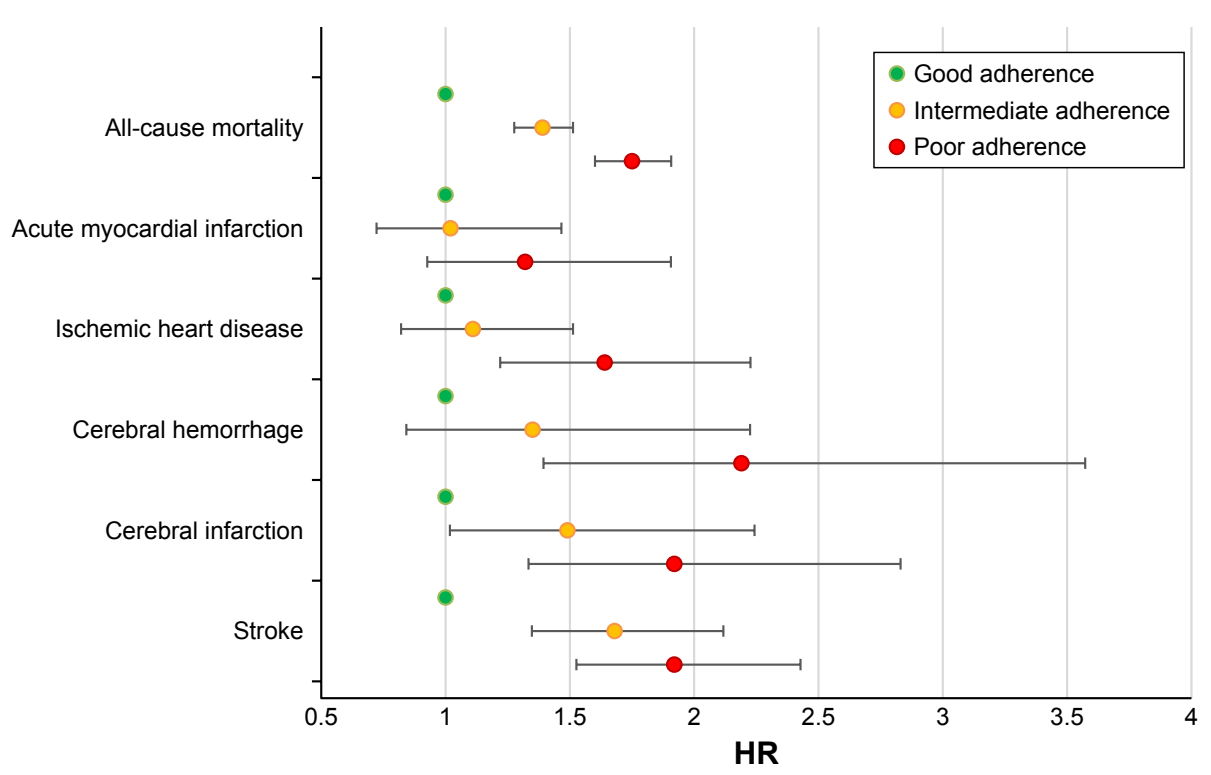

Figure 3 Mortality risks of non-adherence to antihypertensives in cardiovascular disease.

Notes: Cohort sizes for good, intermediate, and poor adherences were $N=12,647, N=10,846$, and $N=11,223$, respectively. Data were adjusted using common clinical factors and patient identifiers, with bars indicating $95 \% \mathrm{Cl}$. Data were adapted from Kim S, Shin DW, Yun JM, et al. Medication adherence and the risk of cardiovascular mortality and hospitalization among patients with newly prescribed antihypertensive medications. Hypertension. 2016;67:506-512.44

Table I Diagnostic tools for adherence testing

\begin{tabular}{|c|c|c|c|c|c|c|}
\hline \multirow{2}{*}{$\begin{array}{l}\text { Adherence } \\
\text { diagnosis } \\
\text { method }\end{array}$} & \multirow[t]{2}{*}{ Subjective? } & \multicolumn{2}{|c|}{ Objective? } & \multirow[t]{2}{*}{ Description of use } & \multirow[t]{2}{*}{ Strengths } & \multirow[t]{2}{*}{ Weaknesses } \\
\hline & & Indirect? & Direct? & & & \\
\hline $\begin{array}{l}\text { Physician } \\
\text { perception }\end{array}$ & $\checkmark$ & \multicolumn{2}{|c|}{$x$} & $\begin{array}{l}\text { Physician clinically judging } \\
\text { patients' adherence }\end{array}$ & $\begin{array}{l}\text { Simple, quick, and non- } \\
\text { invasive }\end{array}$ & Capacity of perception is poor \\
\hline $\begin{array}{l}\text { Patient } \\
\text { self-report } \\
\text { methods }\end{array}$ & $\checkmark$ & \multicolumn{2}{|c|}{$x$} & $\begin{array}{l}\text { Patient reporting their } \\
\text { own adherence, usually } \\
\text { through use of a validated } \\
\text { questionnaire }\end{array}$ & $\begin{array}{l}\text { Easy to administer and } \\
\text { may find rationale for } \\
\text { adherence }\end{array}$ & $\begin{array}{l}\text { Potential to overreport or falsify } \\
\text { adherence; can be intrusive for } \\
\text { some patients }\end{array}$ \\
\hline $\begin{array}{l}\text { Reviewing } \\
\text { pharmacy } \\
\text { records }\end{array}$ & $x$ & $\checkmark$ & $x$ & $\begin{array}{l}\text { Reviewing patient } \\
\text { pharmacy visits to acquire } \\
\text { medication }\end{array}$ & $\begin{array}{l}\text { Provides data on } \\
\text { prevalence of adherence } \\
\text { behavior over time }\end{array}$ & $\begin{array}{l}\text { Accuracy of results depends on } \\
\text { accuracy of records }\end{array}$ \\
\hline Pill counting & $x$ & $\checkmark$ & $x$ & $\begin{array}{l}\text { Counting remaining pills } \\
\text { after a set period }\end{array}$ & $\begin{array}{l}\text { Can give information on } \\
\text { non-adherence rates for } \\
\text { a particular medication }\end{array}$ & $\begin{array}{l}\text { Time consuming and can easily be } \\
\text { manipulated by a patient }\end{array}$ \\
\hline $\begin{array}{l}\text { Electronic } \\
\text { monitoring } \\
\text { devices }\end{array}$ & $x$ & $\checkmark$ & $x$ & $\begin{array}{l}\text { Devices, such as pill } \\
\text { dispensers, which provide } \\
\text { a record of use }\end{array}$ & $\begin{array}{l}\text { Gives plentiful, } \\
\text { continuous information } \\
\text { (eg, dosing times and } \\
\text { patterns) }\end{array}$ & $\begin{array}{l}\text { Expensive; poorly integrates with } \\
\text { the elderly; lack of mainstream } \\
\text { multimedication monitoring systems }\end{array}$ \\
\hline $\begin{array}{l}\text { Directly } \\
\text { observed } \\
\text { therapy }\end{array}$ & $x$ & $x$ & $\checkmark$ & $\begin{array}{l}\text { Continuous observation } \\
\text { of patient by practitioner, } \\
\text { in a clinical setting }\end{array}$ & $\begin{array}{l}\text { Provides a confident } \\
\text { yes/no adherence } \\
\text { answer }\end{array}$ & $\begin{array}{l}\text { Intrusive and potentially dangerous } \\
\text { for non-adherent patients who } \\
\text { ingest their previously avoided } \\
\text { medications }\end{array}$ \\
\hline Digital pills & $x$ & $x$ & $\checkmark$ & $\begin{array}{l}\text { Pills that can record use, } \\
\text { to a localized sensor, } \\
\text { after ingestion }\end{array}$ & $\begin{array}{l}\text { Provides precise time } \\
\text { of ingestion data }\end{array}$ & Expensive and limited availability \\
\hline $\begin{array}{l}\text { Biochemical } \\
\text { testing }\end{array}$ & $x$ & $x$ & $\checkmark$ & $\begin{array}{l}\text { Detecting parent drug, } \\
\text { drug metabolite, or } \\
\text { biomarker in a patients' } \\
\text { bodily fluids }\end{array}$ & $\begin{array}{l}\text { Finds definitive yes/no } \\
\text { adherence snap shot }\end{array}$ & $\begin{array}{l}\text { Labor intensive; current methods } \\
\text { (screens) provide only data on most } \\
\text { recent ingestion, methods are not } \\
\text { widespread, and adherence may be } \\
\text { skewed by drug pharmacokinetics }\end{array}$ \\
\hline
\end{tabular}

Notes: A comparison of adherence testing methods detailing strengths and weaknesses of either approach. Information sourced from Gupta et al. ${ }^{10}$ 


\section{Subjective versus objective measures}

Hess et $\mathrm{a}^{46}$ reported that the most commonly utilized tests for non-adherence diagnoses are comparable as they determine similar rates. However, physician perception on true adherence has been described as "no better than a coin toss". A study found less than $50 \%$ of the patients were correctly identified as being non-adherent when using these measures. ${ }^{47}$

Self-reports are more accurate than a physician's perception and are generally adaptations of the common Morisky scale. ${ }^{48}$ They can give information about a patients' reasoning for their non-adherence behavior, which is impossible by objective methods alone ${ }^{49}$ However, self-reports are exposed to biases that can overestimate adherence by $10 \%-20 \%{ }^{50}$ Furthermore, patients with low literacy or psychological ailments may have issues with completing a self-report and is therefore not a robust metric.

The National Institute for Health and Care Excellence (NICE) reported that the major barrier for improving adherence was the lack of a robust, objective tool for real-world diagnosis. ${ }^{51}$ Indirect objective methods can give detailed information about adherence patterns through time. Yet, they cannot provide concrete evidence regarding the ingestion of the medication.

Direct objective approaches can provide definitive answers to ingestion, although digital pills and observed therapy are limitedly available, expensive, and potentially dangerous. On the contrary, biochemical testing through the detection of physiological markers, parent drug, or drug metabolite in bodily fluids has become increasingly used as they by-pass patient intrusion while accurately determining the ingestion of the treatment. The $2018 \mathrm{ESC} / \mathrm{ESH}$ guidelines have endorsed biochemical testing as the preferred nonadherence test because they are among the most accurate methods. ${ }^{2}$

\section{Matrices for biochemical testing}

Most body matrices could be used for assessing adherence, with urine and blood being the current standard in CVD. ${ }^{2}$ Despite the lack of standardization, a large proportion of methods have been developed for urinary analysis by screening drugs qualitatively (present/not present), and to a lesser extent, quantitatively (measurement of exact concentrations). ${ }^{11,29,52-54}$ One developed screen has a vast library for CVD medication detection by liquid chromatography tandem mass spectrometry (LC-MS/MS). It is capable of identifying 40 of the most commonly prescribed medications for comprehensive urinary adherence testing, ${ }^{11}$ and the technique is arguably the least invasive of the body matrices available for analysis. A simple sample preparation is required prior to analysis, and the process from collection to result is robust and efficient. ${ }^{55}$

Blood and its derivatives have been used to determine and quantify cardiovascular drug levels in circulating blood post-dose. ${ }^{56}$ Unlike urine, these methods allow the detection of drugs that are extensively metabolized or have a low urinary excretion. Traditionally, the main drawback for blood-based matrices was the large volume of blood $(5-10 \mathrm{~mL})$ that is collected for routine toxicology testing. Nevertheless, methods have been validated for large libraries of cardiometabolic drugs. For example, one method was capable of detecting 55 drugs. ${ }^{57}$

Bernieh et al ${ }^{58}$ developed and successfully validated a novel adherence quantitation method for the determination of 10 cardiovascular drugs from dried blood spots (DBS), which used significantly less blood volume than earlier methods ( $20 \mu \mathrm{L}$ total). The researchers have since optimized their method, coupling the specialized use of microsampling devices with DBS analysis to bypass hematocrit problems previously experienced. ${ }^{59}$ Volumetric absorptive microsampling was used to collect very precise and accurate volumes of blood (10-20 $\mu \mathrm{L})$, which could allow samples to be selfcollected for routine adherence testing. This technique is highly promising, but the main drawback is the small amount of drugs currently targeted $(\mathrm{N}=4)$. With further development, a large targeted library may be possible for application in cardiometabolic diseases.

Akin to practices in forensic toxicology, hair analysis for non-adherence testing is possible. To date, no study has explored hair for adherence testing in cardiometabolic diseases, but a method for COPD medications (eg, formoterol and salmeterol) has been developed. ${ }^{60}$ The authors of this novel method stated that it could provide a record of historical adherence, overcoming a major issue for single spot-urine and blood samples. Hair collection is not routine in clinical visits and could be considered intrusive by nature as head collection leaves a small bald spot on the posterior vertex region of the scalp.

An emerging concept for adherence testing is the biochemical analysis of breath condensates, whereby exhaled breath can monitor biomarkers of endogenous or endogenous compounds. ${ }^{61}$ The matrix is simple and non-invasive, where sample collection is straightforward and analysis could be done on-site at the time of sample collection. ${ }^{62}$ Near-patient testing is the gold standard researchers should aspire to investigate, as it drastically reduces the time to gauge adherence so that patients can derive a quicker therapeutic benefit. 
Obstacles such as the low drug concentrations present in the matrices, and the lack of standardization, pose difficulties prior to development.

\section{Screening urine for non-adherence testing}

Urine is a common choice of matrix as its characteristics have been previously validated to assess its appropriateness. For example, cardiometabolic drug stabilities have been shown to be mostly uncompromised within the urine at room temperature over 3 days. ${ }^{63}$ This is an important consideration for testing centers that receive samples by mail, as transport is cheaper and sample collection can occur in a wider radius from a testing hub. More patients can therefore gain therapeutic benefits using established urinary-based techniques.

Physicians can confidently discuss the best option for non-adherent patients in a tailored manner using the existing urine screens. A follow-up study of hypertension patients explored the use of biochemical analysis of urine for adherence and found that by the final clinical visit for initially nonadherent patients $(\mathrm{N}=73)$, the ratio of detected to prescribed AH drugs increased from 0.33 to 1.00 after intervention. ${ }^{64}$ This coincided with a significant mean decrease in systolic and diastolic blood pressures of 19.5 and $7.5 \mathrm{mmHg}$, respectively, showing an efficacious procedure for symptom control. This approach, therefore, has high therapeutic potential for application in other cardiometabolic diseases, although a long-term study is required to gauge persistence and relapses to tailored therapies.

\section{Established testing centers}

The need for biochemical adherence testing has driven the development of centers with suitable analyzers that provide the service to the health care industry. For example, the National Centre for Adherence Drug Testing (NCAT), based in the UK, offers an extensive urinary screen for $>60$ medications by LC-MS/MS (Table 2). Analyzers available for non-adherence screening differ greatly and are chosen dependent on the availability, cost, and suitability.

LC-MS/MS is widely used for chemical analysis of varying matrices due to having a high sensitivity and a diverse range of applications. ${ }^{65}$ LC-MS/MS separates molecules by chemical affinity to either stationary phase or mobile phase. Molecules are then ionized and fragmented to create predictable daughter ion masses that are indicative of parent ions. With the ability to simultaneously detect fragmentation transitions using multiple reaction monitoring, the analyzer can identify multiple drugs, which is ideal for screening.
Table 2 National Centre for Adherence Drug Testing: current list of detectable urinary medications in the screen for nonadherence

\begin{tabular}{|c|c|}
\hline Drug class & Medications \\
\hline \multirow{5}{*}{$\begin{array}{l}\text { Angiotensin-converting enzyme } \\
\text { inhibitors }\end{array}$} & Enalapril \\
\hline & Lisinopril \\
\hline & Perindopril \\
\hline & Ramipril \\
\hline & Trandolapril \\
\hline \multirow[t]{8}{*}{ Calcium channel blockers } & Amlodipine \\
\hline & Diltiazem \\
\hline & Felodipine \\
\hline & Lacidipine \\
\hline & Lercanidipine \\
\hline & Nicardipine \\
\hline & Nifedipine \\
\hline & Verapamil \\
\hline \multirow[t]{9}{*}{ Diuretics } & Amiloride \\
\hline & Bendroflumethiazide \\
\hline & Bumetanide \\
\hline & Eplerenone \\
\hline & Furosemide \\
\hline & Hydrochlorothiazide \\
\hline & Indapamide \\
\hline & Spironolactone \\
\hline & Triamterene \\
\hline \multirow[t]{6}{*}{ Angiotensin II receptor antagonists } & Candesartan \\
\hline & Irbesartan \\
\hline & Losartan \\
\hline & Olmesartan \\
\hline & Telmisartan \\
\hline & Valsartan \\
\hline \multirow[t]{7}{*}{ Beta blockers } & Atenolol \\
\hline & Bisoprolol \\
\hline & Carvedilol \\
\hline & Labetalol \\
\hline & Metoprolol \\
\hline & Nebivolol \\
\hline & Propranolol \\
\hline \multirow[t]{9}{*}{ Miscellaneous } & Alfuzosin \\
\hline & Clonidine \\
\hline & Doxazosin \\
\hline & Ivabradine \\
\hline & Minoxidil \\
\hline & Moxonidine \\
\hline & Nicorandil \\
\hline & Prazosin \\
\hline & Ranolazine \\
\hline
\end{tabular}


Table 2 (Continued)

\begin{tabular}{|l|l|}
\hline Drug class & Medications \\
\hline Anticoagulant/antiplatelet drugs & Apixaban \\
\cline { 2 - 2 } & Clopidogrel \\
\cline { 2 - 2 } & Dabigatran \\
\cline { 2 - 2 } & Rivaroxaban \\
\hline Antilipid drugs & Atorvastatin \\
\cline { 2 - 2 } & Rosuvastatin \\
\hline Antidiabetic drugs & Metformin \\
\hline \multirow{5}{*}{ Sulfonylureas } & Glibenclamide \\
\cline { 2 - 2 } & Gliclazide \\
\cline { 2 - 2 } & Glimepiride \\
\cline { 2 - 2 } & Glipizide \\
\hline Meglitinides & Nateglinide \\
\cline { 2 - 2 } & Repaglinide \\
\hline Glitazones & Pioglitazone \\
\hline Gliptins & Linagliptin \\
\cline { 2 - 2 } & Saxagliptin \\
\cline { 2 - 2 } & Sitagliptin \\
\hline \multirow{5}{*}{ SGLT-2 inhibitors } & Canagliflozin \\
\cline { 2 - 2 } & Dapagliflozin \\
\cline { 2 - 2 } & Empagliflozin \\
\hline
\end{tabular}

Future testing centers will likely incorporate this technology as LC-MS/MS has fast become the gold standard for small molecule detection because of their high sensitivity, throughput, and simple sample preparation. ${ }^{66}$

\section{Limitations of biochemical screening for adherence}

Currently, the use of analyzers like an LC-MS/MS for biochemical non-adherence is not widespread. Biochemical testing is often thought of as expensive due to the initial cost of investing in highly sensitive analytical instruments, which can cost upwards of $\$ 300,000$. The requirement of skilled laboratory workers is also a limitation in its widespread use. A hub and spoke model has been envisaged for this type of adherence testing, allowing the use of specialized equipment in a few centers to span across a country to further reduce the cost. ${ }^{57}$ In addition, health economic models have shown biochemical testing to be cost-efficient, as the higher accuracy of these devices can better identify non-adherence and reduce unnecessary investigations and treatments. ${ }^{67}$

Adherence is not a static construct and is known to vary over time due to numerous determinates. Indeed, a screen assay represents metabolites and parent drugs of consumed medication, with the result signifying the end product of behavior at a given moment. Hence, the snapshot works adequately as a screening tool; however, there is presently no data about its correlation with long-term non-adherence or cardiovascular outcomes.

A quantification assay could provide more information about dosing behavior and could better identify test manipulation (eg, "tooth brush effect", the increased adherence prior to a clinic visit). ${ }^{68}$ These assays may be better suited as concentrations could provide information relating to when the dose was ingested. However, they require complex sample preparation and analysis procedures and require extensive validation. Quantifications have been developed, yet in DM, there are few used for non-adherence. ${ }^{69} \mathrm{~A}$ meta-analysis explains the reasoning for this as it found no guidelines regarding the use of biochemical testing for DM adherence, and hence no standard has been set for assay developement. ${ }^{5}$

\section{Limitations of urine as a matrix}

Non-adherence found using biochemical testing is dependent on the pharmacokinetics of medications, such as half-life, bioavailability, and urinary excretion. The different chemical structures between medications lead to unique dispositions within the body and diverse elimination routes. Differences between drug pharmacokinetic parameters can therefore be stark, as shown between amlodipine and metformin that have half-lives of 39 and 1.7 hours, respectively. ${ }^{70}$ It is probable that drugs with extreme half-lives may appear non-adherent when in reality they have been ingested outside of the screens detectable window. This has been previously highlighted by Hamdidouche et al who noted the potential risk of variable drug pharmacokinetics in causing false-negatives in urinary screens. ${ }^{71}$ However, to date, no study has extensively evaluated the effect of pharmacokinetics on adherence in these assays.

Urine is a suitable matrix for detecting exogenously derived drugs, but with the recent development and introduction of protein-based therapeutics like PCSK9i, urinary analysis will not be possible. These drugs undergo proteolytic degradation and will not be excreted renally (under normal conditions), and so biochemical non-adherence testing will need to be done for biomarkers in blood. On the other hand, these drugs are not widely prescribed and so their current influence in future adherence testing development is minimal.

\section{Conclusion}

Clinically, urinary screens are the most useful non-adherence tools currently available for cardiometabolic diseases. They routinely provide high accuracy measures for many drugs and are evidenced to incur good adherence in the real-world setting. Without exploring the relationship between drug pharmacokinetics and urine screens, true adherence found 
using biochemical testing will remain ambiguous for certain drugs. Furthermore, biochemical screens can only signify the end product of adherence behavior, and so multiple follow ups may be needed for long-term therapeutic drug monitoring. This review highlights that further research should be conducted to investigate other biological matrices and analytical methods for non-adherence testing, especially for blood, quantifications, and near-patient techniques. These offer huge promise but are not extensively developed. Longterm non-adherence outcomes in cardiometabolic disease found using biochemical testing should also be conducted, as most outcomes have been found by subjective and indirect methods.

\section{Acknowledgment}

The authors acknowledge the support of the National Institute for Health Research (NIHR) Collaboration for Leadership in Applied Health Research and Care-East Midlands (CLARHC-EM) and NIHR Leicester Biomedical Research Centre.

\section{Disclosure}

Kamlesh Khunti has been a consultant, speaker, and advisory board member for Amgen, AstraZeneca, Novartis, Novo Nordisk, Sanofi-Aventis, Lilly, Merck Sharp \& Dohme, Janssen, and Boehringer Ingelheim. He has also received grants in support of investigator-initiated trials from AstraZeneca, Novartis, Novo Nordisk, Sanofi-Aventis, Lilly, Boehringer Ingelheim, Merck Sharp \& Dohme, and Roche. Kamlesh Khunti reports personal fees from AstraZeneca, Bayer, AstraZeneca, Lilly, Merck Sharp \& Dohme, Novartis, Novo Nordisk, Roche, Sanofi-Aventis, and Berlin-Chemie AG/Menarini Group. The authors report no other conflicts of interest in this work.

\section{References}

1. Gupta R, Sharma KK, Gupta BK, et al. Geographic epidemiology of cardiometabolic risk factors in middle class urban residents in India: cross-sectional study. J Glob Health. 2015;5:150-162. doi:10.7189/ jogh.05.010411

2. Williams B, Mancia G, Spiering W, et al; ESC Scientific Document Group. ESC/ESH guidelines for the management of arterial hypertension. Eur Heart J. 2018;2018(39):3021-3104.

3. World Health Organisation. Adherence to Long-Term Therapies: Evidence for Action. WHO; 2003:11. Available from: http://www.who.int/ chp/knowledge/publications/adherence_report/en/. Accessed August 2, 2018.

4. Kotseva K, Wood D, De Bacquer D, et al; EUROASPIRE Investigators. EUROASPIRE IV: a European society of cardiology survey on the lifestyle, risk factor and therapeutic management of coronary patients from 24 European countries. Eur J Prev Cardiol. 2016;23:636-648. doi: $10.1177 / 2047487315569401$

5. Khunti K, Seidu S, Kunutsor S, Davies M. Association between adherence to pharmacotherapy and outcomes in type 2 diabetes: a metaanalysis. Diabetes Care. 2017;40:1588-1596. doi:10.2337/dc16-1925
6. Parekh N, Ali K, Stevenson JM, et al. Incidence and cost of medication harm in older adults following hospital discharge: a multicentre prospective study in the UK. Br J Clin Pharmacol. 2018;84(8):1789-1797. doi: $10.1111 /$ bcp. 13613

7. Egede LE, Gebregziabher M, Dismuke CE, et al. Medication nonadherence in diabetes: longitudinal effects on costs and potential cost savings from improvement. Diabetes Care. 2012;35:2533-2539. doi:10.2337/ dc $12-0572$

8. Haynes RB, McDonald H, Garg AX, Montague P. Interventions for helping patients to follow prescriptions for medications. Cochrane Database Syst Rev. 2002;CD000011.

9. Nieuwlaat R, Wilczynski N, Navarro T, et al. Interventions for enhancing medication adherence. Cochrane Database Syst Rev. 2014;11: 1-732;CD000011.

10. Gupta P, Patel P, Horne R, Buchanan H, Williams B, Tomaszewski M. How to screen for non-adherence to antihypertensive therapy. Curr Hypertens Rep. 2016;18:1-8. doi:10.1007/s11906-015-0615-4

11. Tomaszewski M, White C, Patel P, et al. High rates of non-adherence to antihypertensive treatment revealed by high-performance liquid chromatography-tandem mass spectrometry (HP LC-MS/MS) urine analysis. Heart. 2014;100(11):855-861. doi:10.1136/heartjnl-2013-305063

12. GBD 2016 Causes of Death Collaborators. Global, regional, and national age-sex specific mortality for 264 causes of death, 1980-2016: a systematic analysis for the global burden of disease study 2016. Lancet. 2017;390:1151-1210. doi:10.1016/S0140-6736(17)32152-9

13. World Health Organisation. Global report on diabetes. 2016. Available from: http://www.who.int/diabetes/global-report/en/. Accessed October 3, 2018.

14. Cho NH, Shaw JE, Karuranga S, et al. IDF Diabetes Atlas: global estimates of diabetes prevalence for 2017 and projections for 2045. Diabetes Res Clin Pract. 2018;138:271-281. doi:10.1016/j.diabres.2018.02.023

15. Diabetes fact sheet. World Health Organization web site. [Updated 2017]. Available from: http://www.who.int/news-room/fact-sheets/ detail/diabetes. Accessed Oct 3, 2018.

16. Centers for Disease Control and Prevention. National Diabetes Statistics Report: Estimates of Diabetes and its Burden in the United States, 2014. Atlanta (GA): US Department of Health and Human Services; 2014.

17. Kronish IM, Ye S. Adherence to cardiovascular medications: lessons learned and future directions. Prog Cardiovasc Dis. 2013;55:590-600. doi:10.1016/j.pcad.2013.02.001

18. Sjölander M, Eriksson M, Glader E. The association between patients' beliefs about medicines and adherence to drug treatment after stroke: a cross-sectional questionnaire survey. BMJ Open. 2013;3:e03551. doi:10.1136/bmjopen-2013-003551

19. Dias A, Pereira C, Monteiro MJ, Santos C. Patients' beliefs about medicines and adherence to medication in ischemic heart disease. Aten Primaria. 2014;46(Suppl 5):101-106. doi:10.1016/S0212-6567(14) 70074-5

20. Gupta P, Mohamed AA, Patel P, et al. High rates of non-adherence to antidiabetic, antihypertensive and lipid lowering treatment in patients with type 2 diabetes revealed liquid chromatography-tandem mass spectrometry (lc-ms/ms) urine analysis. Atheroscler Suppl. 2018;34:e2. doi:10.1016/j.atherosclerosissup.2018.07.021

21. Cohen JD, Brinton EA, Ito MK, Jacobson TA. Understanding statin use in America and gaps in patient education (USAGE): an internetbased survey of 10,138 current and former statin users. J Clin Lipidol. 2012;6:208-215. doi:10.1016/j.jacl.2012.03.003

22. Chaudhary R, Garg J, Shah N, Sumner A. PCSK9 inhibitors: a new era of lipid lowering therapy. World J Cardiol. 2017;9:76-91. doi:10.4330/ wjc.v9.i2.76

23. Gragnano F, Concilio C, Cesaro A, et al. P1513 Adherence to PCSK9 inhibitors in high cardiovascular risk patients in real-world setting: results from a single-center experience and comparison with statin therapy. Eur Heart J. 2017;38:134.

24. Saborowski M, Dölle M, Manns MP, LeitolfH, Zender S. Lipid-lowering therapy with PCSK9-inhibitors in the management of cardiovascular high-risk patients: effectiveness, therapy adherence and safety in a real world cohort. Cardiol J. 2018;25:32-41. doi:10.5603/CJ.a2017.0137 
25. Fortin M, Bravo G, Hudon C, Vanasse A, Lapointe L. Prevalence of multimorbidity among adults seen in family practice. Ann Family Med. 2005;3:223-228. doi:10.1370/afm.272

26. Cassell A, Edwards D, Harshfield A, et al. The epidemiology of multimorbidity in primary care: a retrospective cohort study. Br J Gen Pract. 2018;68:e251. doi:10.3399/bjgp18X694949

27. Wallace E, Salisbury C, Guthrie B, Lewis C, Fahey T, Smith SM. Managing patients with multimorbidity in primary care. BMJ. 2015;350:176. doi:10.1136/bmj.h176

28. Marcum ZA, Gellad WF. Medication adherence to multi-drug regimens. Clin Geriatr Med. 2012;28:287-300. doi:10.1016/j.cger.2012. 01.008

29. Gupta P, Patel P, Štrauch B, et al. Risk factors for nonadherence to antihypertensive treatment. Hypertension. 2017;69:1113-1120. doi:10.1161/HYPERTENSIONAHA.116.08729

30. NICE-The National Institute for Health and Care Excellence. Simvastatin. BNF: British National Formulary - NICE web site. [Updated 2019]. Available from: https://bnf.nice.org.uk/medicinal-forms/simvastatin.html\#PHP76700. Accessed January 28, 2019.

31. NICE-The National Institute for Health and Care Excellence. Ezetimibe. BNF: British national formulary - NICE web site. [Updated 2019]. Available from: https://bnf.nice.org.uk/medicinal-forms/ezetimibe. html. Accessed January 28, 2019.

32. NICE-The National Institute for Health and Care Excellence. Simvastatin with ezetimibe. BNF: British national formulary - NICE web site. [Updated 2018]. Available from: https://bnf.nice.org.uk/medicinalforms/simvastatin-with-ezetimibe.html. Accessed August 9, 2018.

33. Chowdhury R, Khan H, Heydon E, et al. Adherence to cardiovascular therapy: a meta-analysis of prevalence and clinical consequences. Eur Heart J. 2013;34:2940-2948. doi:10.1093/eurheartj/eht295

34. Polonsky WH, Henry RR. Poor medication adherence in type 2 diabetes: recognizing the scope of the problem and its key contributors. Patient Prefer Adherence. 2016;10:1299-1307. doi:10.2147/PPA.S106821

35. Iglay K, Cartier SE, Rosen VM, et al. Meta-analysis of studies examining medication adherence, persistence, and discontinuation of oral antihyperglycemic agents in type 2 diabetes. Curr Med Res Opin. 2015;31:1283-1296. doi:10.1185/03007995.2015.1053048

36. Lin L, Sun Y, Heng BH, Chew DEK, Chong P. Medication adherence and glycemic control among newly diagnosed diabetes patients. BMJ Open Diabetes Res Care. 2017;5:e000429. doi:10.1136/bmjdrc2017-000429

37. Hong JS, Kang HC. Relationship between oral antihyperglycemic medication adherence and hospitalization, mortality, and healthcare costs in adult ambulatory care patients with type 2 diabetes in South Korea. Med Care. 2011;49:378-384. doi:10.1097/MLR.0b013e31820292d1

38. Lau DT, Nau DP. Oral antihyperglycemic medication nonadherence and subsequent hospitalization among individuals with type 2 diabetes. Diabetes Care. 2004;27:2149-2153.

39. Currie CJ, Peyrot M, Morgan CL, et al. The impact of treatment noncompliance on mortality in people with type 2 diabetes. Diabetes Care. 2012;35:1279-1284. doi:10.2337/dc11-1277

40. Kim Y, Lee J, Kang H, Park SM. Effect of medication adherence on long-term all-cause-mortality and hospitalization for cardiovascular disease in 65,067 newly diagnosed type 2 diabetes patients. Sci Rep. 2018;8(1):12190-12197. doi:10.1038/s41598-018-30740-y

41. Naderi SH, Bestwick JP, Wald DS. Adherence to drugs that prevent cardiovascular disease: meta-analysis on 376,162 patients. Am J Med. 2012;125:882.e1-887.e1. doi:10.1016/j.amjmed.2011.12.013

42. Kolandaivelu K, Leiden BB, O'Gara PT, Bhatt DL. Non-adherence to cardiovascular medications. Eur Heart J. 2014;35:3267-3276. doi:10.1093/eurheartj/ehu364

43. Ho PM, Spertus JA, Masoudi FA, et al. Impact of medication therapy discontinuation on mortality after myocardial infarction. Arch Intern Med. 2006;166:1842-1847. doi:10.1001/archinte.166.17.1842

44. Kim S, Shin DW, Yun JM, et al. Medication adherence and the risk of cardiovascular mortality and hospitalization among patients with newly prescribed antihypertensive medications. Hypertension. 2016;67: 506-512. doi:10.1161/HYPERTENSIONAHA.115.06731
45. Velligan DI, Wang M, Diamond P, et al. Relationships among subjective and objective measures of adherence to oral antipsychotic medications. Psychiatr Serv. 2007;58:1187-1192. doi:10.1176/ps.2007.58.9.1187

46. Hess LM, Raebel MA, Conner DA, Malone DC. Measurement of adherence in pharmacy administrative databases: a proposal for standard definitions and preferred measures. Ann Pharmacother. 2006;40: 1280-1288. doi:10.1345/aph.1H018

47. Meddings J, Kerr EA, Heisler M, Hofer TP. Physician assessments of medication adherence and decisions to intensify medications for patients with uncontrolled blood pressure: still no better than a coin toss. BMC Health Serv Res. 2012;12:270. doi:10.1186/1472-6963-12-270

48. Shi L, Liu J, Fonseca V, Walker P, Kalsekar A, Pawaskar M. Correlation between adherence rates measured by MEMS and self-reported questionnaires: a meta-analysis. Health Qual Life Outcomes. 2010;8:99. doi:10.1186/1477-7525-8-99

49. Morisky DE, Ang A, Krousel-Wood M, Ward HJ. Predictive validity of a medication adherence measure in an outpatient setting. $J$ Clin Hypertens (Greenwich). 2008;10:348-354.

50. Voils CI, Hoyle RH, Thorpe CT, Maciejewski ML, Yancy WS. Improving the measurement of self-reported medication nonadherence. J Clin Epidemiol. 2011;64:250-254. doi:10.1016/j.jclinepi.2010.07.014

51. Medicines adherence (NICE guideline 76). NICE Web site. [Updated 2009]. Available from: https://www.nice.org.uk/guidance/CG76. Accessed September 26, 2018.

52. Ewen S, Meyer MR, Cremers B, et al. Blood pressure reductions following catheter-based renal denervation are not related to improvements in adherence to antihypertensive drugs measured by urine/plasma toxicological analysis. Clin Res Cardiol. 2015;104:1097-1105. doi:10.1007/ s00392-015-0905-5

53. Jung O, Gechter JL, Wunder C, et al. Resistant hypertension? assessment of adherence by toxicological urine analysis. J Hypertens. 2013; 31:766-774. doi:10.1097/HJH.0b013e32835e2286

54. Lawson AJ, Shipman KE, George S, Dasgupta I. A novel 'Dilute-andshoot' liquid chromatography-tandem mass spectrometry method for the screening of antihypertensive drugs in urine. J Anal Toxicol. 2016;40:17-27. doi:10.1093/jat/bkv102

55. Gupta P, Patel P, Tomaszewski M. Measurements of Antihypertensive Medications in Blood and Urine. In: Burnier M, editor. Drug Adherence in Hypertension and Cardiovascular Protection. Updates in Hypertension and Cardiovascular Protection. Cham: Springer; 2018:29.

56. Turner RM, Fontana V, Bayliss M, Whalley S, Santoyo Castelazo A, Pirmohamed M. Development, validation and application of a novel HPLC-MS/MS method for the quantification of atorvastatin, bisoprolol and clopidogrel in a large cardiovascular patient cohort. JPharm Biomed Anal. 2018;159:272-281. doi:10.1016/j.jpba.2018.06.062

57. Gonzalez O, Alonso RM, Ferreirós N, Weinmann W, Zimmermann R, Dresen S. Development of an LC-MS/MS method for the quantitation of 55 compounds prescribed in combined cardiovascular therapy. J Chromatogr B. 2011;879:243-252. doi:10.1016/j.jchromb.2010.12.007

58. Bernieh D, Lawson G, Tanna S. Quantitative LC-HRMS determination of selected cardiovascular drugs, in dried blood spots, as an indicator of adherence to medication. J Pharm Biomed Anal. 2017;142:232-243. doi:10.1016/j.jpba.2017.04.045

59. Tanna S, Alalaqi A, Bernieh D, Lawson G. Volumetric absorptive microsampling (VAMS) coupled with high-resolution, accurate-mass (HRAM) mass spectrometry as a simplified alternative to dried blood spot (DBS) analysis for therapeutic drug monitoring of cardiovascular drugs. Clin Mass Spectrom. 2018;10:1-8.

60. Hassall D, Brealey N, Wright W, et al. Hair analysis to monitor adherence to prescribed chronic inhaler drug therapy in patients with asthma or COPD. Pulm Pharmacol Ther. 2018;51:59-64. doi:10.1016/j.pupt.2018.07.001

61. Kubáň P, Foret F. Exhaled breath condensate: determination of nonvolatile compounds and their potential for clinical diagnosis and monitoring. A review. Anal Chim Acta. 2013;805:1-18. doi:10.1016/j. aca.2013.07.049

62. Khoubnasabjafari M, Rahimpour E, Jouyban A. Exhaled breath condensate as an alternative sample for drug monitoring. Bioanalysis. 2018;10:61-64. doi:10.4155/bio-2017-0205 
63. Burns AD, Lane D, Cole R, Patel P, Gupta P. Cardiovascular medication stability in urine for non-adherence screening by LC-MS-MS. J Anal Toxicol. 2018;bky090.

64. Gupta P, Patel P, Štrauch B, et al. Biochemical screening for nonadherence is associated with blood pressure reduction and improvement in adherence. Hypertension. 2017;70:1042-1048. doi:10.1161/ HYPERTENSIONAHA.117.09631

65. Pitt JJ. Principles and applications of liquid chromatography-mass spectrometry in clinical biochemistry. Clin Biochem Rev. 2009;30:19

66. Leung KS, Fong BM. LC-MS/MS in the routine clinical laboratory: has its time come? Anal Bioanal Chem. 2014;406:2289-2301. doi:10.1007/ s00216-013-7542-5

67. van Schoonhoven AV, van Asselt ADI, Tomaszewski M, et al. Costutility of an objective biochemical measure to improve adherence to antihypertensive treatment. Hypertension. 2018;72(5):1117-1124. doi:10.1161/HYPERTENSIONAHA.118.11227
68. Chatterjee JS. From compliance to concordance in diabetes. $J$ Med Ethics. 2006;32(9):507-510. doi:10.1136/jme.2005.012138

69. Forbes CA, Deshpande S, Sorio-Vilela F, et al. A systematic literature review comparing methods for the measurement of patient persistence and adherence. Curr Med Res Opin. 2018;34:1613-1625. doi:10.1080/ 03007995.2018.1477747

70. Brunton LL, Chabner BA, Knollmann BC. Goodman \& Gilman's the Pharmacological Basis of Therapeutics. 12 ed. New York: McGrawHill; 2011.

71. Hamdidouche I, Jullien V, Boutouyrie P, Billaud E, Azizi M, Laurent S. Drug adherence in hypertension: from methodological issues to cardiovascular outcomes. J Hypertens. 2017;35(6):1133-1144. doi:10.1097/ НЈH.0000000000001299

\section{Publish your work in this journal}

Patient Preference and Adherence is an international, peer-reviewed, open access journal that focuses on the growing importance of patient preference and adherence throughout the therapeutic continuum. Patient satisfaction, acceptability, quality of life, compliance, persistence and their role in developing new therapeutic modalities and compounds to optimize clinical outcomes for existing disease states are major areas of interest for the journal. This journal has been accepted for indexing on PubMed Central. The manuscript management system is completely online and includes a very quick and fair peer-review system, which is all easy to use. Visit http://www. dovepress.com/testimonials.php to read real quotes from published authors.

Submit your manuscript here: http://www.dovepress.com/patient-preference-and-adherence-journal 